\title{
PENGARUH DEMULSIFIER A DAN DEMULSIFIER B TERHADAP CRUDE OIL BENTAYAN DENGAN METODE BOTTLE TEST DEMULSIFIER
}

\author{
Dian Kurnia Sari ${ }^{1)}$, Nidia Sauqi ${ }^{2)}$ \\ ${ }^{1,2)}$ Program studi Teknik Analisis Laboratorium Migas Politeknik Akamigas Palembang, 30257, Indonesia
}

\begin{abstract}
Abstrak: Pada penelitian ini dilakukan pengujian demulsifier untuk proses demulsifikasi crude oil Bentayan, agar diperoleh nilai pemisahan air yang baik. Karakteristik fisika dan kimia seperti specific gravity, pour point, viscosity kinematic, asphaltene content dan basic sediment and water (BS\&W) menunjukkan bahwa crude oil Bentayan adalah heavy medium crude oil dan mempunyai emulsi yang sangat stabil dengan jenis emulsi air dalam minyak W/O. Demulsifier yang digunakan ialah demulsifier A dan demulsifier B dimana untuk mengetahui pengaruh dari demulsifier tersebut terhadap crude oil Bentayan maka dilakukan pengujian bottle test demulsifier dengan pengaruh konsentrasi demulsifier, temperatur pengujian, waktu interaksi dan nilai basic sediment and water $(B S \& W)$. Dari pengujian tersebut didapatkan pemisahan air yang baik terjadi pada konsentrasi 30 ppm, temperatur pengujian $60^{\circ} \mathrm{C}$ dan waktu interaksi (settling time) 60 menit. Pada crude oil Bentayan proses demulsifikasi yang baik menggunakan demulsifier $B$ dibandingkan dengan demulsifier A dimana demulsifier B menunjukkan \% waterdrop mencapai $100 \%$, \% interface adalah $0 \%$ dan \% BS\&W sebesar 0,1 \%vol. Hal ini juga memungkinkan demulsifier B lebih baik dilihat dari pengujian fourier transform infra red (FTIR) dimana demulsifier B mempunyai gugus -OH yang memungkinkan dapat mengikat air dari crude oil Bentayan. Dengan hasil tersebut maka dapat diketahui bahwasanya demulsifier B lebih baik pada proses demulsifikasi crude oil Bentayan.
\end{abstract}

Kata Kunci : Minyak Mentah, Emulsi, Demulsifier.

\section{PENDAHULUAN}

Salah satu energi yang paling banyak digunakan bersumber dari minyak bumi (petroleum). Minyak bumi yang belum diolah disebut minyak mentah (crude oil), minyak mentah merupakan campuran yang kompleks, mulai dari hidrokarbon sebagai komponen utama dan komponen - komponen lain seperti sulfur, nitrogen, oksigen, logam, asphaltene, wax, base sediment and water (BS\&W) dan padatan (suspended solid). Salah satu komponen minyak mentah yang dapat memberikan masalah bagi proses produksi yaitu adanya air didalam minyak mentah, dimana air tersebut akan membentuk emulsi. Emulsi pada minyak mentah ini distabilkan oleh zat - zat kimia alami yang terkandung dalam minyak, seperti asphaltene, resin dan wax yang dikenal sebagai interfacial active components atau surfaktan alami. Emulsi dalam minyak mentah sangat tidak diharapkan karena tetesan air (water droplet) dan garam garam $\left(\mathrm{NaCl}, \mathrm{MgCl}_{2}, \mathrm{CaCl}_{2}\right.$ dan $\left.\mathrm{KCl}\right)$ yang terperangkap pada minyak mentah dapat menyebabkan korosi pada pipa dan peralatan kilang minyak bumi. Oleh karena itu, air yang terdispersi dalam emulsi minyak mentah harus dipisahkan.

Karakteristik minyak mentah sangat mempengaruhi kestabilan emulsinya, sedangkan minyak mentah yang berasal dari daerah berbeda mempunyai sifat karakteristik yang berbeda pula. Untuk itu, perlu diketahui karakteristik minyak mentah Indonesia dan kestabilan emulsinya agar bisa didapatkan penanganan yang tepat untuk proses pengolahan selanjutnya. Pemisahan air dari emulsi minyak mentah dapat dilakukan dengan metode mekanik, termal, elektrik dan proses kimiawi (Grace, 1992). Diantara keempat metode tersebut, perlakuan secara kimiawi menggunakan demulsifier dapat menghasilkan efisiensi pemisahan yang paling baik dibandingkan dengan metode lainnya. Oleh karena itu, metode secara kimia banyak diaplikasikan di industri dengan mengintegrasikan beberapa metode, seperti metode pemisahan secara kimia 
dikombinasikan dengan metode termal dapat meningkatkan efisiensi pemisahan air pada minyak mentah. Demulsifier merupakan kelas bahan kimia khusus yang digunakan untuk memisahkan emulsi pada minyak mentah sehingga dapat menghasilkan kualitas minyak mentah yang lebih baik dan biaya produksi yang efisien. Demulsifier yang digunakan dalam pengujian ini, yaitu demulsifier A dan demulsifier B, karena tidak semua demulsifier dapat digunakan untuk semua jenis minyak mentah maka, dilakukan pemeriksaan karakteristik fisika dan kimia minyak mentah Bentayan agar sesuai dengan demulsifier yang akan digunakan.

\section{TEORI DASAR}

Emulsi didefinisikan sebagai suatu sistem yang terdiri dari dua fasa cairan yang tidak saling melarutkan (immiscible liquid) yang distabilkan oleh emulsifier (surfaktan), dimana salah satu fasa cairan terdispersi dalam cairan lainnya. Cairan yang terpecah menjadi butir - butir dinamakan fasa terdispersi, sedangkan cairan yang mengelilingi butiran butiran itu disebut fasa continue atau medium dispersi.

\subsection{Jenis-jenis Emulsi}

a. Berdasarkan ukuran partikel fasa terdispersi

Berdasarkan ukuran partikelnya, emulsi dibagi menjadi tiga jenis, yaitu :

1. Makroemulsi

Makroemulsi merupakan emulsi yang paling banyak dijumpai. Makroemulsi merupakan emulsi non transparan dengan ukuran fasa terdispersi lebih besar dari 400 $\mathrm{nm}(0,4 \mu \mathrm{m})$.

2. Mikroemulsi

Mikroemulsi merupakan emulsi transparan dengan ukuran fasa terdispersi lebih kecil dari $100 \mathrm{~nm}(0,1 \mu \mathrm{m})$.

3. Nanoemulsi

Nanoemulsi merupakan emulsi dengan ukuran fasa terdispersi diantara 100-400 nm $(0,1-0,4 \mu \mathrm{m})$.

Warna emulsi dalam crude oil, berkaitan dengan ukuran tetesan dimana kebanyakan emulsi berwarna merah kegelapan, abu abu, cokelat dan hitam kecokelatan. Ukuran tetesan emulsi lebih kecil memiliki luas permukaan yang besar, sehingga akan membentuk warna yang lebih terang. Sebaliknya tetesan berukuran lebih besar akan menyebabkan terbentuknya emulsi yang lebih gelap. Secara fisik bila emulsi tersebut kelihatan buram (tidak jernih) berarti ukuran partikel dari fasa terdispersi kira - kira $7 \mu \mathrm{m}$ dan bila emulsi kelihatan jernih dan tembus pandang berarti ukuran partikel fasa terdispersi kurang dari $0,1 \mu \mathrm{m}$.

b. Berdasarkan kondisi dari fasa terdispersi

Secara umum, jenis emulsi dapat digolongkan dalam dua kelompok yaitu air dan minyak. Jika air terdispersi dalam minyak maka disebut jenis emulsi air dalam minyak (W/O) seperti yang diilustrasikan pada gambar 2.5. Dengan demikian air sebagai fasa terdispersi dan minyak sebagai fasa kontinyu. Sebaliknya jika minyak terdispersi ke air maka emulsi tersebut merupakan jenis emulsi minyak dalam air $(\mathrm{O} / \mathrm{W})$. Disamping itu terdapat kemungkinan jenis emulsi yang lain seperti water - in - oil - in - water emulsion (W/OW) atau oil - in - water - in - oil emulsion $(\mathrm{O} / \mathrm{W} / \mathrm{O})$ seperti pada gambar 2.6. Secara alamiah emulsi minyak mentah biasanya merupakan jenis emulsi water - in oil (air sebagai fasa terdispersi dan minyak sebagai fasa kontinyu) dan emulsi ini bersifat stabil karena adanya kandungan aspal dan resin dalam minyak mentah yang dapat membentuk film yang menyelimuti butir air (aspal atau resin bertindak sebagai penstabil emulsi).

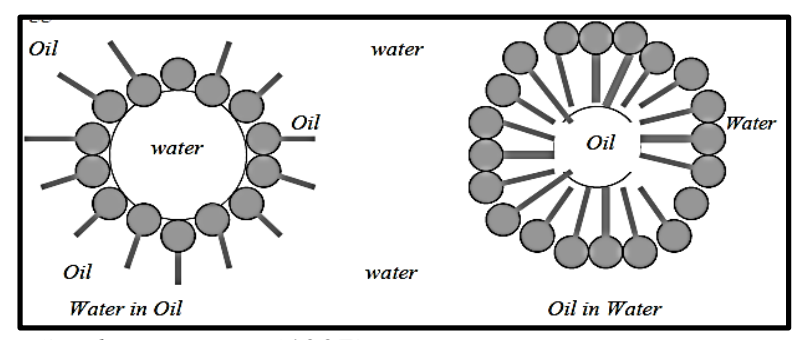

Sumber : Prince (1997)

Gambar 2.1 Skema Jenis O/W dan W/O Pada Emulsi Tunggal 


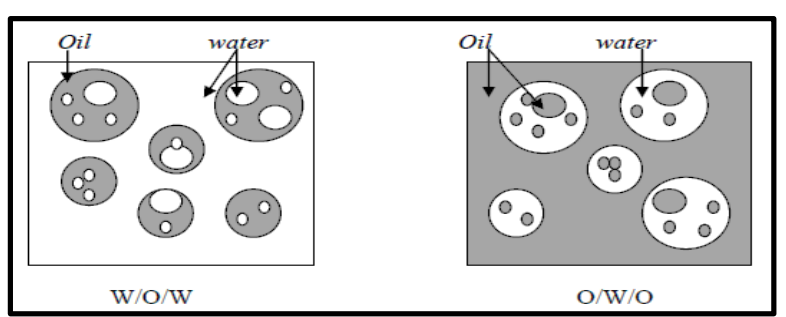

Sumber: Hunter (1989)

\section{Gambar 2.2 Skema Emulsi Ganda W/O/W dan $\mathrm{O} / \mathrm{W} / \mathrm{O}$}

\subsection{Pembentukan Emulsi}

Sesuai dengan definisi emulsi, maka terbentuknya emulsi disebabkan oleh tiga faktor, yaitu :

a. Cairan yang tidak saling melarutkan

Dalam operasi produksi minyak bumi pada umumnya diperoleh minyak dan air secara bersamaan, dimana antara minyak dan air bersifat tidak saling melarutkan, kondisi ini akan cenderung membentuk air dalam minyak (W/O emulsion). Bila terjadi kenaikan water cut atau terjadi proses water treatment akan memungkinkan terjadi perubahan jenis emulsi minyak dalam air (O/W emulsion), dimana minyak menjadi fasa terdispersi dan air menjadi fasa kontinyu.

b. Terjadinya proses pengadukan (agitasi)

Untuk dapat terbentuknya emulsi pada minyak harus terjadi proses pengadukan, misalnya gelembung gas bergerak melewati campuran minyak - air atau akibat campuran air - minyak melewati celah kecil dengan kecepatan relatif tinggi. Pembentukan emulsi pada umumnya terjadi dari beberapa tingkat pada waktu produksi. Sumber proses agitasi yang cukup untuk dapat membentuk emulsi, diantaranya terjadi pada waktu :

1. Minyak atau air masuk kedalam sumur (minyak dan air mengalir dari formasi melewati lubang perforasi).

2. Pengangkatan buatan yaitu dengan pompa maupun gaslift.

3. Aliran fluida pada tubing, flowline, valve dan jepitan yang dapat menimbulkan turbulensi aliran yang akan memecahkan partikel minyak sehingga potensial untuk terbentuk emulsi.
4. Penurunan
tekanan
dan

temperatur fluida produksi.

\subsubsection{Pengertian Demulsifikasi}

Demulsifikasi adalah pemisahan emulsi menjadi fasa - fasa penyusun dalam hal ini memecah emulsi minyak mentah menjadi fasa minyak dan fasa air. Dalam proses, minyak adalah hasil yang diinginkan. Ada dua aspek dalam demulsifikasi yaitu kecepatan pemisahan emulsi yang terjadi dan jumlah air yang meninggalkan minyak mentah sesudah pemisahan. Terbentuknya emulsi dalam crude oil menimbulkan banyak kerugian dalam industri minyak bumi. Semakin banyak asphaltene yang terkandung akan meningkatkan konsentrasi air yang terkandung dalam crude oil, meningkatkan viskositas crude oil. Menurunkan kualitas minyak bumi dan mengganggu proses produksi. Proses demulsifikasi ini bertujuan untuk memecahkan emulsi pada crude oil sehingga fasa air dan minyak terpisah. Pemisahan yang baik pada crude oil adalah pemisahan yang dapat memisahkan air dari minyak mentah secara cepat hingga didapatkan nilai $\mathrm{BS} \& \mathrm{~W}$ yang rendah di bawah $0,5 \%$.

\subsection{Metode-metode Demulsifikasi}

Pada prinsipnya pemecahan emulsi minyak mentah dapat dilakukan dengan jalan destabilisasi terhadap interfacial active components yang ada dalam minyak mentah tersebut, sehingga sistem emulsi tidak stabil dengan ditandai terpisahnya fasa air dari fasa minyak. Dalam industri minyak telah dikembangkan beberapa metode mendestabilkan emulsi untuk memisahkan air dan minyak pada crude oil, yaitu sebagai berikut :

a. Metode fisis

Metode fisis dapat dilakukan dengan bermacam cara, yaitu :

\section{Pemanasan}

Pemanasan akan memperbanyak pemecahan atau pemisahan, menurunkan viskositas minyak sehingga akan menaikan kecepatan pemisahan air. Temperatur dinaikan juga akan menurunkan stabilitas film. Dengan kata lain panas akan mempercepat proses 
pemecahan emulsi.

2. Penurunan kecepatan aliran.

Penurunan kecepatan aliran akan diikuti pemisahan secara gravitasi dari air terhadap minyak.

3. Merubah karakteristik fisika dari emulsi.

Karakteristik fisika emulsi seperti viskositas jika diturunkan maka air akan mudah terpisah dari minyak atau emulsi karena dengan viskositas turun akan menyebabkan air lebih mudah bergerak.

b. Metode listrik

Metode ini dilakukan menggunakan medan listrik. Bidang medan listrik dapat memecah emulsi minyak mentah - air yang stabil (Aske, et.al., 2002). Medan listrik akan mengganggu film antar muka yang kaku dengan cara penataan kembali molekul-molekul polar. Dengan cara tersebut ikatan film menjadi lemah dan akan memperbanyak pengelompokan (Kokal, 2005).

c. Metode kimia

Metode kimia paling umum digunakan untuk memecah emulsi yaitu dengan menambahkan zat kimia yang disebut demulsifier. Zat kimia tersebut dirancang untuk menetralkan pengaruh pemicu pengemulsi yang menstabilkan emulsi. Demulsifier adalah senyawa aktif permukaan dan jika ditambahkan ke emulsi zat pemicu tersebut akan berpindah ke lapisan antarmuka minyak - air atau memperlemah film yang kaku serta akan memperbanyak pengelompokan butiran air. Pada pemakaian metode kimia yang perlu diperhatikan adalah pemilihan dan jumlah zat kimia yang cocok, pencampuran, $\mathrm{pH}$, kecukupan waktu dan suhu (Kokal, 2005).

\subsection{Fourier Transform Infra Red (FTIR)}

Fourier transform infra red (FTIR) merupakan salah satu alat yang dapat digunakan untuk identifikasi senyawa, khususnya senyawa organik. Analisis dilakukan dengan melihat bentuk spektrumnya yaitu dengan melihat puncak - puncak spesifik yang menunjukkan jenis gugus fungsional yang dimiliki oleh senyawa tersebut. Pada dasarnya spektrofotometer fourier transform infra red adalah sama dengan spektrofotometer infrared dispersi, yang membedakannya adalah pengembangan pada sistem optiknya sebelum berkas sinar inframerah melewati contoh. Pada sistem optik FTIR digunakan radiasi LASER (Light Amplification by Stimulated Emmission of Radiation) yang berfungsi sebagai radiasi yang diinterferensikan dengan radiasi inframerah agar sinyal radiasi inframerah yang diterima oleh detektor secara utuh dan lebih baik. Analisis menggunakan FTIR memiliki beberapa kelebihan utama dibandingkan dengan metode konvensional, yaitu :

1. Dapat digunakan pada semua frekuensi dari sumber cahaya secara simultan sehingga analisis dapat dilakukan lebih cepat.

2. Sensitifitas dari metoda spektrofotometri FTIR lebih besar dari pada cara dispersi, sebab radiasi yang masuk ke sistem detektor lebih banyak karena tanpa harus melalui celah.

3. METODOLOGI PENELITIAN 3.1 Skema Peneletitian

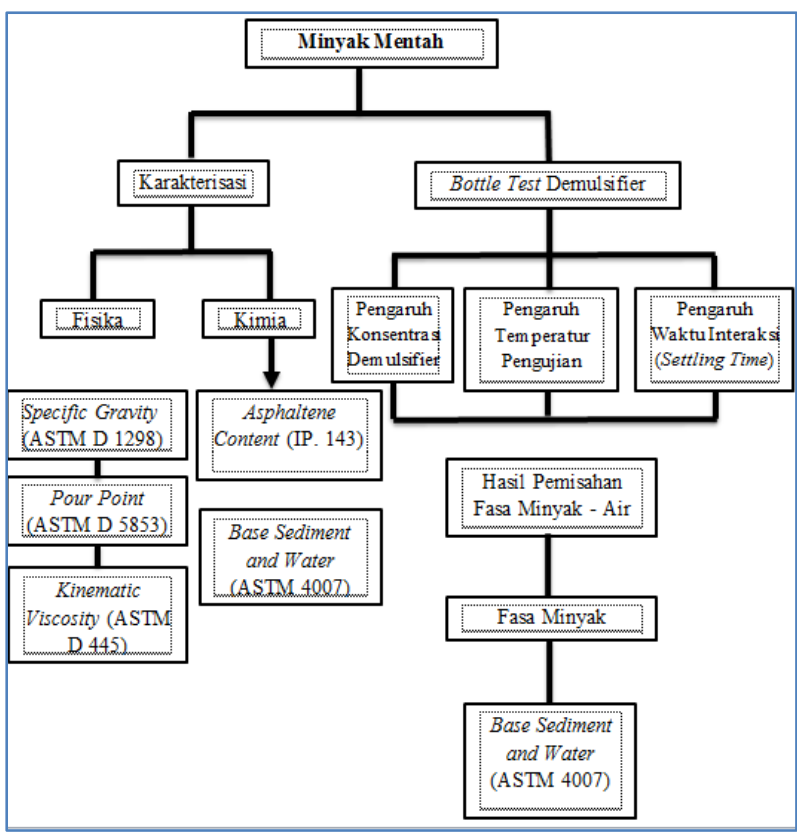

Gambar 3.1 Skema Penelitian

\section{HASIL DAN PEMBAHASAN \\ 4.1 Pengaruh Konsentrasi Demulsifier}

Konsentrasi demulsifier yang digunakan untuk memecah emulsi air dalam 
minyak yang distabilkan oleh asphaltene sebanding dengan konsentrasi asphaltene pada batas antar muka emulsi.
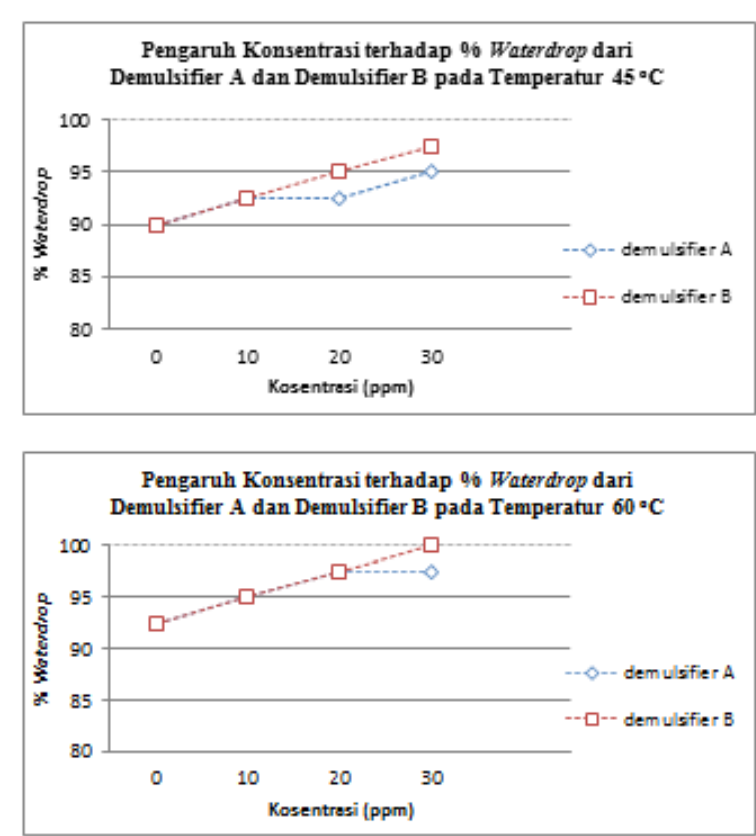

Gambar 4.1 Grafik Pengaruh Konsentrasi Terhadap \% Waterdrop

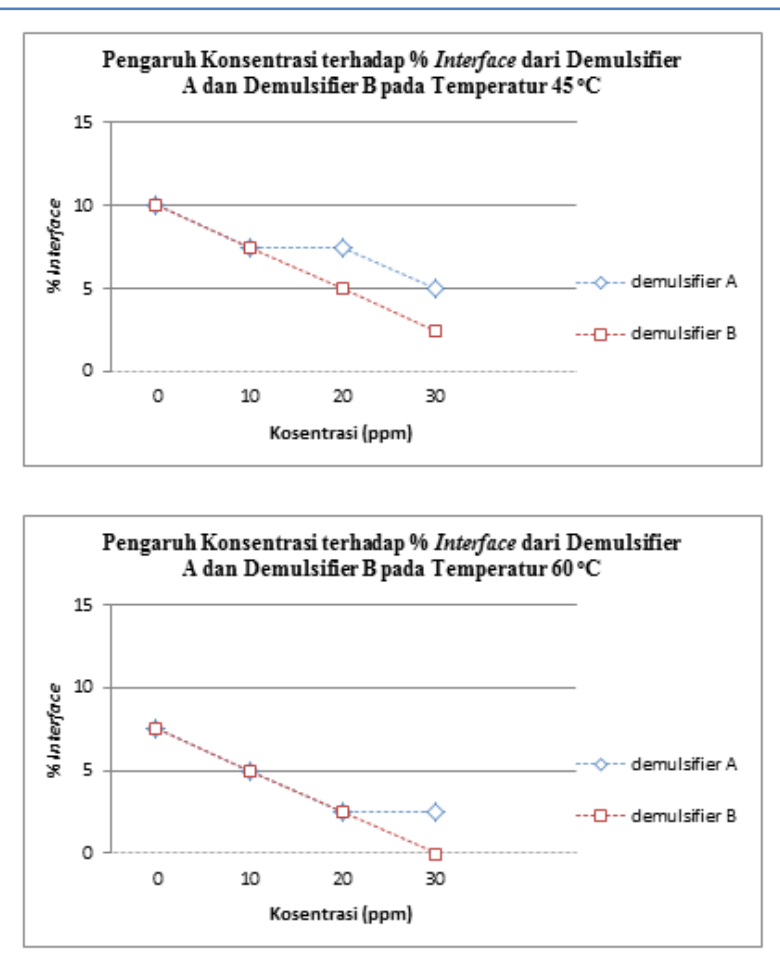

Gambar 4.2 Grafik Pengaruh Konsentrasi Terhadap \% Interface
Demulsifier yang digunakan dalam proses demulsifikasi pada crude oil Bentayan ialah demulsifier A dan demulsifier B yang mempunyai variasi konsentrasi 10 ppm, 20 ppm dan 30 ppm.
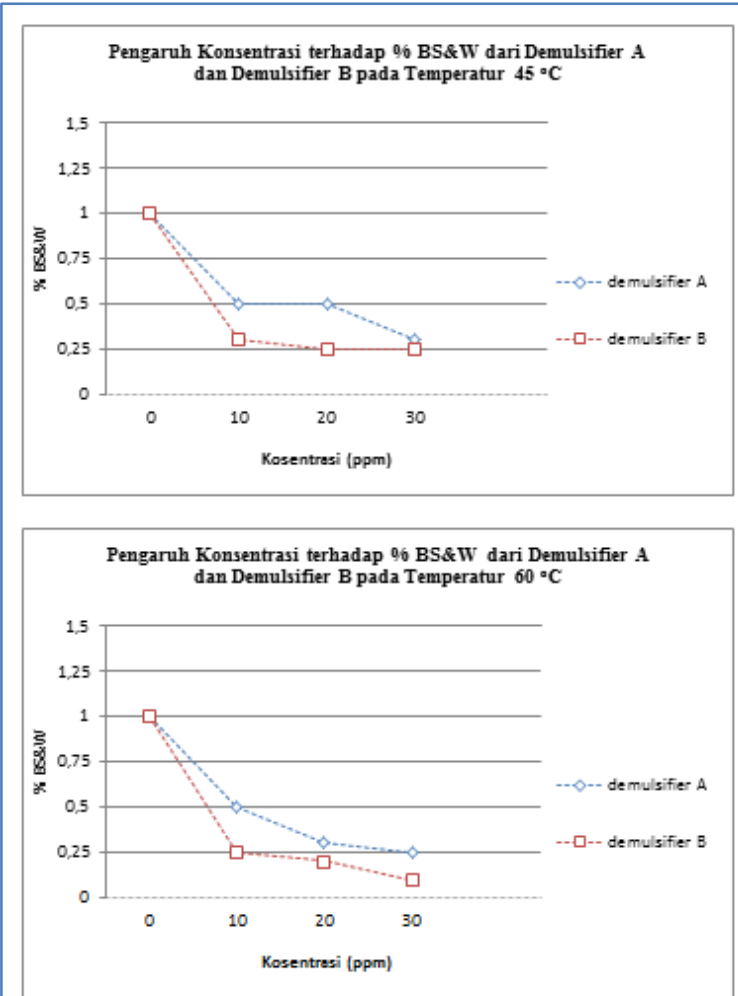

\section{Gambar 4.3 Grafik Pengaruh Konsentrasi Terhadap \% BS\&W}

Gambar 4.1, gambar 4.2 dan gambar 4.3 menunjukkan bahwa variasi konsentrasi digunakan untuk melihat pengaruh dari demulsifier A dan demulsifier B terhadap proses demulsifikasi, sehingga dapat dilihat $\%$ waterdrop, \% interface dan \% BS\&W-nya.

Dari gambar di atas dapat kita ketahui bahwasanya \% waterdrop akan berbanding terbalik dengan \% interface dan \% BS\&W dimana semakin tinggi nilai \% waterdrop maka \% interface dan \% BS\&W semakin kecil, begitupun sebaliknya. Hal ini menunjukkan bahwa pemisahan air dari fasa minyak akan semakin baik apabila nilai \% waterdrop nya meningkat dan nilai $\%$ interface dan \% BS\&W nya semakin rendah. Pada crude oil Bentayan proses demulsifikasi yang baik terjadi dengan konsentrasi $30 \mathrm{ppm}$ baik pada temperatur $60{ }^{\circ} \mathrm{C}$ dari demulsifier $\mathrm{B}$ 
dimana $\%$ waterdrop mengalami pemisahan hingga $100 \%$ dan \% interface yang didapat adalah $0 \%$ serta $\%$ BS\&W nya sebesar 0,1 \%vol. Hasil ini menunjukkan bahwa semakin besar dosis atau konsentrasi demulsifier yang digunakan, emulsi pada crude cenderung semakin tidak stabil sehingga $\%$ pemisahan air meningkat. Dengan hasil tersebut maka dapat diketahui bahwasannya demulsifier B lebih baik dibanding dengan demulsifier $\mathrm{A}$ pada proses demulsifikasi crude oil Bentayan yang dipengaruhi oleh konsentrasi.

\subsection{Pengaruh Temperatur Pengujian Bottle Test}

Variasi pemanasan pada temperatur 45 ${ }^{\circ} \mathrm{C}$ dan $60{ }^{\circ} \mathrm{C}$, ini dilakukan untuk melihat kondisi pemisahan air pada proses demulsifikasi dan melihat pengaruh temperatur terhadap mekanisme destabilisasi emulsi. Pada proses ini crude oil Bentayan dipanaskan agar fisiknya berubah membentuk cairan, karena proses demulsifikasi akan berlangsung optimal pada fasa cair. Hasil yang baik didapatkan pada temperatur $60{ }^{\circ} \mathrm{C}$ dimana gambar 4.1 menunjukkan \% waterdrop mengalami peningkatan pada temperatur tersebut, mengingat bahwasannya crude oil Bentayan mengandung fraksi berat yang dominan maka dengan menggunakan temperatur yang tinggi proses demulsifikasi akan berjalan dengan baik. Temperatur yang tinggi akan menurunkan viskositas crude oil dan viskositas antarfasa pada emulsi crude oil. Temperatur memberikan pengaruh signifikan terhadap proses demulsifikasi, sifat fisik dan kimia dari crude oil akan berubah ketika terjadi peningkatan temperatur. Meningkatnya temperatur pemanasan pada crude oil Bentayan akan meningkatnya frekuensi tumbukkan antar tetesan - tetesan emulsi, menurunkan viskositas dan meningkatkan kelarutan senyawa yang terkandung sistem emulsi.

\subsection{Analisa Gugus Fungsi Demulsifier dengan FTIR}

Tipe emulsi minyak mentah sangat dipengaruhi oleh sifat emulsifier alamiah yang menstabilkan emulsi dan rasio fasa air dengan fasa minyak yang membentuk sistem emulsi. Tipe emulsi minyak mentah biasanya membentuk emulsi air dalam minyak (W/O), karena kandungan fasa minyak yang lebih dominan dibandingkan fasa air. Demulsifikasi crude oil Bentayan menggunakan demulsifier A dan demulsifier $\mathrm{B}$, dimana demulsifier ini diteteskan dengan konsentrasi 10 ppm, 20 ppm dan $30 \mathrm{ppm}$ ke dalam crude oil Bentayan lalu dipanaskan dengan variasi temperatur $45{ }^{\circ} \mathrm{C}$ dan $60{ }^{\circ} \mathrm{C}$. Dari data tersebut didapatkan hasil pemisahan air yang baik terjadi pada demulsifier B dengan konsentrasi 30 ppm. Pengujian dengan fourier transform infra red (FTIR) dilakukan untuk menentukan gugus fungsi yang terdapat pada demulsifier A dan demulsifier $\mathrm{B}$ dimana sebanyak 3 tetes demulsifier diletakkan ke dalam tube kompartemen pada FTIR dan dihasilkan spektrogramnya, seperti gambar 4.5.

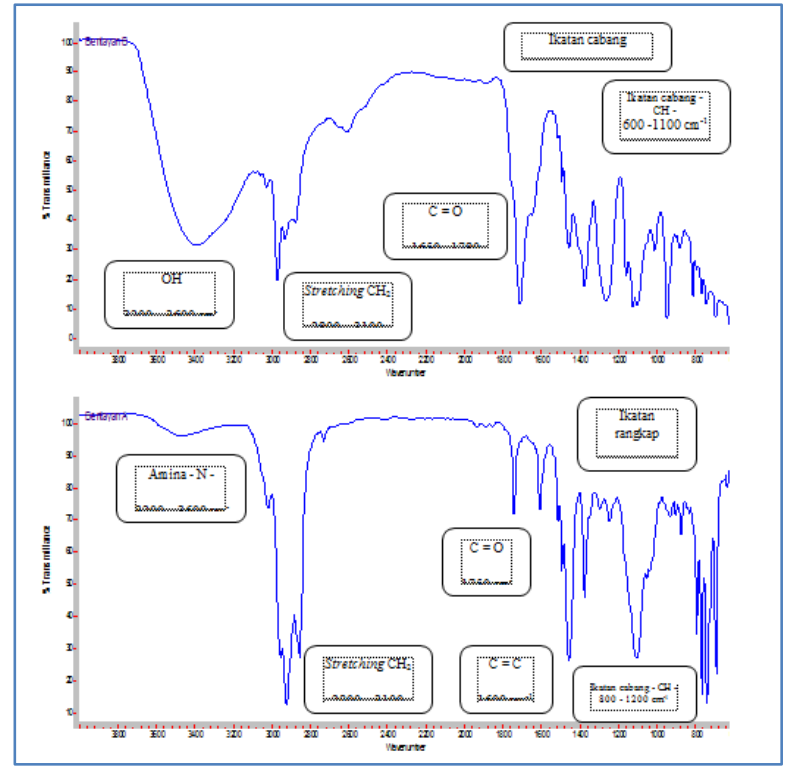

\section{Gambar 4.5 Analisa Gugus Fungsi dengan FTIR}

Dari data yang sudah didapatkan maka demulsifier yang lebih baik ialah demulsifier B dibandingkan dengan demulsifier A. Hal ini memungkinkan bahwasannya pada pemeriksaan FTIR, demulsifier B mempunyai gugus fungsi - $\mathrm{OH}$ yang dapat mengikat emulsi pada crude oil Bentayan mengingat bahwasanya - $\mathrm{OH}$ dapat larut dalam air karena membentuk ikatan hidrogen dengan air. Selain itu, antar molekul alkohol sendiri juga 
membentuk ikatan hidrogen. Karena sifat alkohol adalah polar, maka alkohol menjadi pelarut yang lebih baik untuk molekul molekul polar dari pada hidrokarbon. Namun, juga tidak menutup kemungkinan bahwasannya gugus fungsi amina pada demulsifier A bersifat polar dan dapat mengikat air, mengingat karakteristik senyawa amina dengan jumlah atom karbon dibawah enam biasanya larut dalam air, tapi kelarutannya akan semakin rendah apabilah berat molekulnya semakin besar. Dari kedua gugus fungsi tersebut maka sangat sulit untuk menentukan demulsifier yang dapat mengikat air pada crude oil Bentayan. Oleh sebab itu, dilihat bahan kimia yang sering digunakan dalam proses demulsifikasi crude oil. Surfaktan yang sering digunakan sebagai demulsifier umumnya adalah surfaktan anionik, kationik, nonionik dan ampoterik. Demulsifier umumnya diformulasikan dari jenis-jenis surfaktan sebagai berikut : poliglikol dan poliglikol ester, ethoxylated alcohol, ethoxylated phenol formaldehyde, polyhydric alcohols, ethylene oxide dan garam sulfonat. Dari jenis-jenis surfaktan tersebut dapat diketahui bahwasannya gugus fungsi yang dimiliki oleh demuslifier B ini memungkinkan mempunyai bahan yang hampir sama dengan formulasi demulsifier yang sering digunakan, dibandingkan dengan senyawa amina, dimana alkohol lebih dominan digunakan dalam pembuatan bahan demulsifier. Namun, untuk mengetahui komposisi demulsifier harus dilakukan pengujian lebih lanjut mengingat tidak hanya gugus fungsi yang dapat mempengaruhi proses demulsifikasi crude oil.

\section{KESIMPULAN DAN SARAN}

\subsection{Kesimpulan}

Dari pembahasan tersebut, maka kesimpulan dari penelitian ini, yaitu :

1. Pemisahan air yang baik terjadi pada konsentrasi $30 \mathrm{ppm}$, temperatur pengujian $60{ }^{\circ} \mathrm{C}$ dan waktu interaksi (settling time) 60 menit, dimana hasil tersebut menunjukkan $\%$ waterdrop akan berbanding terbalik dengan $\%$ interface dan $\% \mathrm{BS} \& \mathrm{~W}$, semakin tinggi nilai \% waterdrop maka \% interface dan \% BS\&W semakin kecil, begitupun sebaliknya. Hal ini dapat dipengaruhi oleh semakin tinggi konsentrasi, temperatur dan waktu settling, maka akan meningkatkan pemisahan air dari fasa minyak. Sehingga proses demulsifikasi akan berjalan dengan optimal pada kondisi tersebut.

2. Pada crude oil Bentayan demulsifikasi yang baik menggunakan demulsifier $\mathrm{B}$ dibandingkan dengan demulsifier A dimana demulsifier B pada pengujian bottle test menunjukkan $\%$ waterdrop mencapai 100 $\%$, \% interface adalah $0 \%$ dan $\%$ BS\&W sebesar 0,1 \%vol. Hal ini juga memungkinkan demulsifier B lebih baik dilihat dari pengujian fourier transform infra red (FTIR) dimana demulsifier B mempunyai gugus - $\mathrm{OH}$ yang memungkinkan dapat mengikat air dari crude oil Bentayan.

\section{DAFTAR PUSTAKA}

Auflem, I. H. 2002. Influence of Asphaltene Aggregation \& Pressure on Crude Oil Emulsion Stability. Norwegian : Norwegian University of Science \& Technology.

Fingas, M., Field house, B., Bobra, M., \& Tennyson, E. 2003. The Physics \& Chemistry of Emulsions. Proceed Workshop on Emulsion. Washington DC: Marine Spill Response Corporation.

Grace, R.. 1992. Commercial Emulsion Breaking. In Schramm, L.L. Emulsions Fundamentals \& Applications in the Petroleum Industry. Washington DC : American Chemical Society.

Groenzin, H dan Mullins, O. C., Sheu, E. Y., Hammami, A., Eds. Springer Science. 2007. Asphaltene Molecular Size and Weight by Time-Resolved Fluorescence Depolarization. In Asphaltenes, Heavy Oils, and Petroleomics. New York : Business Media LL. 
Hermonicolet Corporation. 2007. Introduction to Fourier Transform Infrared Spectrometry.

Hardjono, A.. 2001. Teknologi Minyak Bumi. Yogyakarta: Universitas Gajah Mada.

Speight, J. G \& Moschopedis, S.E.. 1999. In Chemistry of Asphaltenes; Bunger, J. W., Li, N. C., Eds.; Advances in Chemistry 195. Washington, DC: American Chemical Society.

Sjooblom, j, Narve Aske, Inge Harald Auflem, Oystein Brandal, Trond Erik Havre, Oystein Sæther, Arild Westvik, Einar Eng Johnsen, Harald Kallevik. 2003. Our current understanding of water-in-crude oil emulsions. New York : Recent characterization techniques and high pressure performance. Advances in Colloid \& Interface Science

Sjoblom, E.E. Johnsen, A. Westvik. 2001. Encyclopedic Handbook of Emulsion Technology. New York: Marcel Dekker.

The Institute of Petroleum 143. 1990. Determination of Asphaltenes (heptanes insolubles) in Crude Petroleum and Petroleum Product. London: The Institute of Petroleum. 
P-ISSN: 2089-5925 E-ISSN: 2621-9328

Antrant

Jurnal Teknik Patra Akademika

PA

A KaAemiKa

Volume 09 No 01 Juli 2018 